\title{
Experimental Comparison of Hyperelastic Model on Skin
}

\author{
Nor Fazli Adull Manan, Jamaluddin Mahmud \\ Faculty of Mechanical Engineering \\ Universiti Teknologi MARA Shah Alam, Selangor \\ Malaysia
}

\begin{abstract}
This study aims to determine the hyperelastic parameters of skin (ovine). Firstly, experimental procedures involving mechanical tensile tests on ovine skin are conducted according to ASTM International Standard. Then, experimental data and hyperelastic model for biomaterials are integrated. Finally, the data are analysed and the results are compared to previous findings published by other researchers. The quantified Ogden hyperelastic parameters for ovine skin are found to be Ogden coefficient, $\mu=0.37 \mathrm{MPa}$ and Ogden exponent, $\alpha=$ 7.60 respectively. This study has contributed significantly in understanding the hyperelastic parameter characterisation.
\end{abstract}

Keywords- Hyperelastic model; skin; biomechanical properties

\section{INTRODUCTION}

Recently many researchers contribute many efforts in quantifying hyperelastic biomaterials especially life skin either from human or animals. One main reason the study carried out is to contribute to the pool of knowledge for better life now and in the future. Highly demanded plastic surgery, veterinary sciences, cosmetic industries and others are other reasons that may contribute to this type of study. Two main objectives for conducting this study are to characterise the biomechanical properties of ovine skin with experimental approach and comparing the findings with others. The comparison was made between human skin [1], silicone rubber [2] and pigskin [3]. All of them [1-3] used uniaxial tensile machine as mechanical test for their specimens. On the other hand, several experimental techniques were available and have been widely used by others as well. For example, suction and pressure measurement were utilised by Hashmi [4] and Hendriks [5] respectively. Indention technique [6] and digital analysis [7,8] were another commands technique that also have been applied. However, the famous method for this experiment is approaching using tension technique and it has been proven that researchers have been applying this into their experiments [9-11]. Thus, this study is vital in order to gain the consistency and accuracy before future in-vivo research on human skin can be carried out.

\section{METHODOLOGY}

Research methodology were divided into three stages. First, experimental procedures that the ovine skin ovine skin has been gone through. Second, the integration of experimental data and hyperelastic model for materials. Finally, analysing the data and comparison of results with other findings. Flowchart portrayed the overall research methodology as in figure 1.

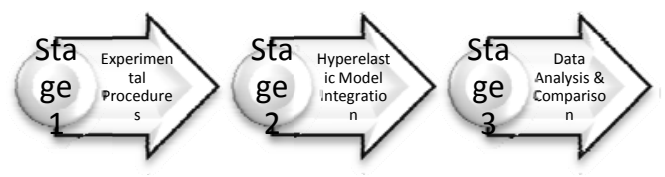

FIGURE I. FLOWCHART OF METHODOLOGY.

A. Experimental ProceduresThe ovine skin was obtained from a young male sheep age 18 months from group of Boer. The fresh ovine skin was purchased from nearby local slaughterhouse. This has been used as the main subject in this study. Before engineering testing procedures take place, the raw material (ovine skin) was gathered to begin the process. The specimens were prepared into dogbone shape according to ASTM International standard. Here, leather standard ASTM (D2209) was utilised. Eight specimens were prepared and tested but only the best four were taken into account. Figure 2 shows specimens of ovine skin. Once the specimens ready, mechanical uniaxial tensile test were performed.

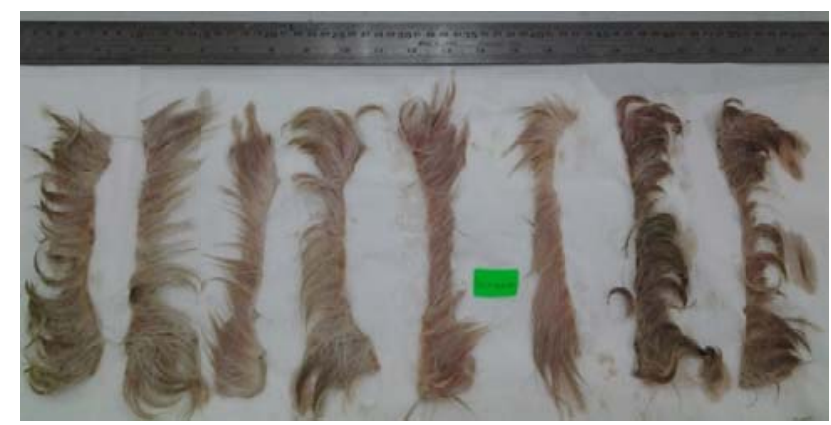

FIGURE II. SPECIMENS OF EXCISED OVINE SKIN.

\section{B. Hyperelastic Model Integration}

As the raw data was obtained from mechanical tests such as strain, elongation, stress and etc, they were converted into hyperelastic parameter i.e stretch and biomechanical properties $(\mu$ and $\alpha$ ). In order to determine the desired biomechanical properties, the hyperelastic model and theory were integrated together with the raw data from the experiment. Figure 3 illustrate the raw experiment data 
obtained. In this specific study, only Ogden Model was used. The Ogden model was derived from strain energy, $W$ equation [12] as in eqn. 1 . Where, $\lambda$ is stretch of skin and $\mu$ also $\sigma$ are Ogden Model coefficient (Biomechanical Properties).

$$
W\left(\lambda_{1}, \lambda_{2}, \lambda_{3}\right)=\sum_{\iota=1}^{N} \frac{\mu_{\iota}}{\alpha_{\iota}}\left(\lambda_{1}^{\alpha \iota}+\lambda_{2}^{\alpha \iota}+\lambda_{3}^{\alpha \iota}-3\right)
$$

Since the case of utilized uniaxial tensile test and one direction were considered, the equation became

$$
\sigma_{e=} \sum_{\iota=1}^{N}\left(\mu_{\iota} \lambda_{e}^{\alpha \iota}-\mu_{\iota} \lambda_{e}^{\frac{-1}{2} \alpha \iota}\right)
$$

After rearranging, the energy equation yielded to,

$$
\sigma_{e}=\left(\frac{\mu}{\lambda}\right)\left[\lambda^{\alpha}-\lambda^{-\frac{\alpha}{2}}\right]
$$

The biomechanical properties of $\mu$ and $\alpha$ became the main subjects in the equation since stress, $\sigma_{\mathrm{e}}$ and stretch; $\lambda$ can be obtained from the raw data. By having these two parameters, the results and findings were further analysed and compared with other results obtained by other researchers.

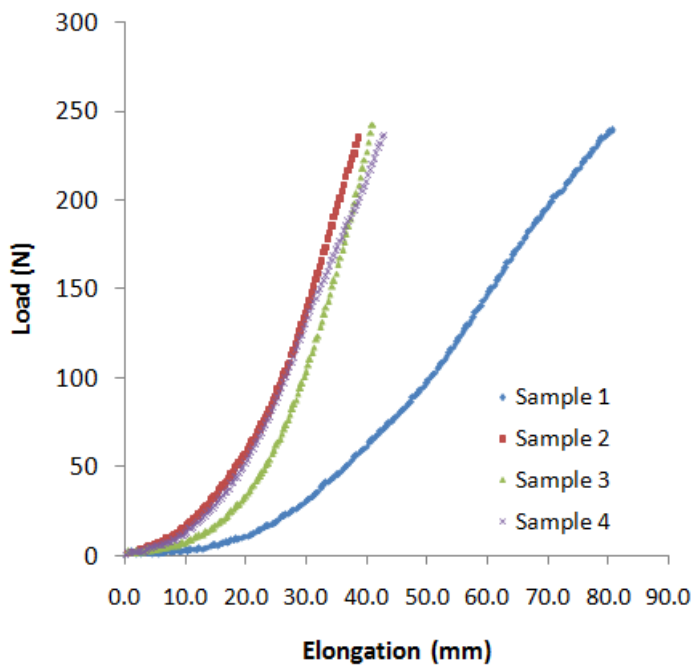

FIGURE III. RAW EXPERIMENT DATA OF OVINE SKIN.

\section{Data Analysis and Comparison}

At this stage, the data was analyzed using analytical analysis, where the biomechanical properties obtained previously were reutilized and re-plotted to investigate the pattern of the graphs either they will form the similar shape or not. Here, the results from other researchers have been matched together for comparison purpose. Figure 4 shows the comparison between current research findings (ovine skin) with silicone, human skin and pigskin.

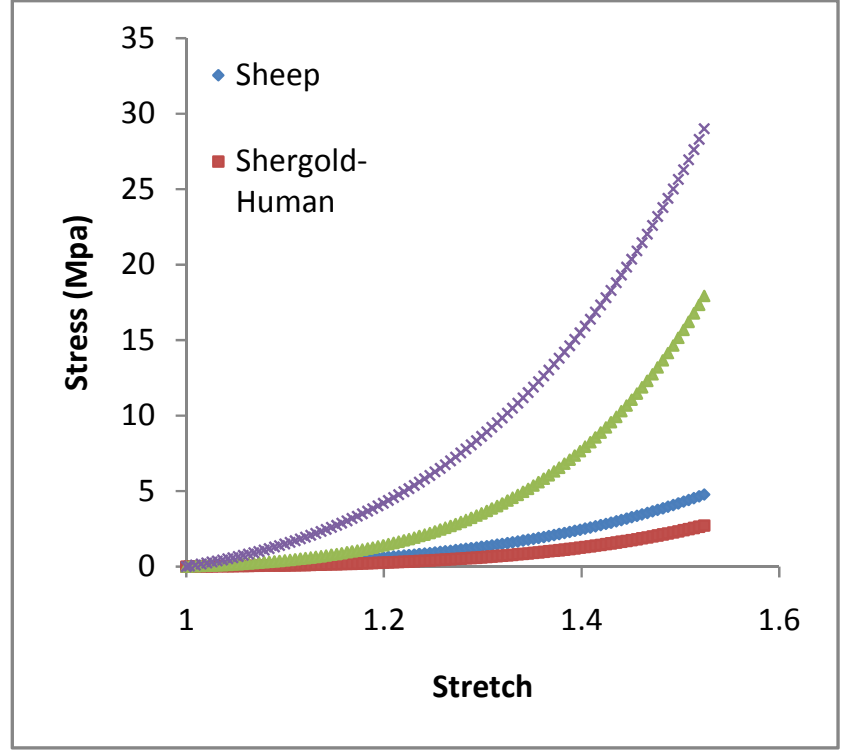

FIGURE IV. COMPARISON OF SKIN AND SILICONE.

\section{RESULT AND DISCUSSION}

As shown in figure 3, the best four experiments data were plotted in line, which plotted graph load vs elongation. Literally the three specimens (sample 2, 3 and 4) lied together and these represented the accuracy and consistency of the testing performed. In addition, the curves formed a regular shape as referring to other finding [13] in their research. By considering one point at the middle of the load around $(125 \mathrm{~N})$, it demonstrated between $30 \mathrm{~mm}$ and $60 \mathrm{~mm}$ of elongation for sample 3 and sample 1 respectively. These gaps and differences between sample 1 and other samples indicated different locations of samples taken from overall ovine skin, where different locations of skin may varied their thickness and compound. The Ogden model Biomechanical properties are ( $\mu$ and $\alpha=0.37$ and 7.60) respectively. Nevertheless figure 4 showed the four type of different subjects that undergone same experimental procedures and hyperelastic model-Ogden. Except ovine skin, human skin, pigskin and silicone were tested by Shergold, Lim and Meunier respectively. Theoretically they represented the right exponential curve shape for all materials used. From the comparison graph, it signified that sheep and human skin have higher elastic characteristic compared to pigskin and silicone. Obviously this represented the accurate and expected findings since pigskin's thickness is higher compared to-human and ovine skin. Furthermore, it justified and verified that the experimental procedures and integration of hyperelastic theory have provided accurate results.

\section{CONCLUSION}

It can be concluded that the study has contributed significantly in understanding the hyperelastic parameter characterization, where the results could be shared with others hyperelastic researchers as reference in the future. Nevertheless, for future recommendation, further investigation on skin location could be done to produce more accurate and consistent experiment findings. 


\section{ACKNOWLEDGMENT}

This research is sponsored by the Ministry of Education (MOE) of Malaysia and Universiti Teknologi MARA (UiTM) Malaysia, grant no FRGS/1/2012/TK01/UITM/02/4 (UiTM File. No. 600-RMI/FRGS 5/3 (25/2012)). The experiments have been conducted at the Strength of Materials Laboratory, Faculty of Mechanical Engineering, Universiti Teknologi MARA, 40450 Shah Alam, with the assistance of dedicated laboratory technicians.

\section{REFERENCES}

[1] A. Shergold, N. A. Fleck, and D. Radford, "The uniaxial stress versus strain response of pig skin and silicone rubber at low and high strain rates," International Journal of Impact Engineering, vol. 32, pp. 1384$1402,2006$.

[2] L. Meunier, G. Chagnon, D. Favier, L. Orgéas, and P. Vacher, "Mechanical experimental characterisation and numerical modelling of an unfilled silicone rubber," Polymer Testing, vol. 27, pp. 765-777, 2008.

[3] J. Lim, J. Hong, W. W. Chen, and T. Weerasooriya, "Mechanical response of pig skin under dynamic tensile loading," International Journal of Impact Engineering, vol. 38, pp. 130-135, 2011.

[4] F. Hashmi and J. Malone-Lee, "Measurement of skin elasticity on the foot," Skin Research and Technology, vol. 13, pp. 252-258, 2007.

[5] F. M. Hendriks, D. Brokken, J. T. W. M. van Eemeren, C. W. J. Oomens, F. P. T. Baaijens, and J. B. A. M. Horsten, "A numerical-experimental method to characterize the non-linear mechanical behavior of human skin," Skin Research and Technology, vol. 9, pp. 274-283, 2003.

[6] J. Jachowicz, R. McMullen, and D. Prettypaul, "Indentometric analysis of in vivo skin and comparison with artificial skin models," Skin Research and Technology, vol. 13, pp. 299-309, 2007

[7] C. Li, S. Li, G. Guan, C. Wei, Z. Huang, and R. K. Wang, "A comparison of laser ultrasound measurements and finite element simulations for evaluating the elastic properties of tissue mimicking phantoms," Optics and Laser Technology, vol. 44, pp. 866-871, 2012.

[8] M. Vogt and H. Ermert, "In vivo ultrasound biomicroscopy of skin: Spectral system characteristics and inverse filtering optimization," IEEE Transactions on Ultrasonics, Ferroelectrics, and Frequency Control, vol. 54 , pp. 1551-1558, 2007.

[9] N. F. Adull Manan, J. Mahmud, M. H. Ismail, and N. H. Arzami, "An Innovative Improvement on Standard Testing Procedure for Biomaterials under Uniaxial Tension," Applied Mechanics and Materials, vol. 393, pp. 130-135, 2013.

[10] A. Ní Annaidh, K. Bruyère, M. Destrade, M. D. Gilchrist, and M. Otténio, "Characterization of the anisotropic mechanical properties of excised human skin," Journal of the Mechanical Behavior of Biomedical Materials, vol. 5, pp. 139-148, 2012.

[11] R. B. Groves, S. A. Coulman, J. C. Birchall, and S. L. Evans, "An anisotropic, hyperelastic model for skin: Experimental measurements, finite element modelling and identification of parameters for human and murine skin," Journal of the Mechanical Behavior of Biomedical Materials, vol. 18, pp. 167-180, 2013.

[12] R. W. Ogden, G. Saccomandi, and I. Sgura, "Fitting hyperelastic models to experimental data," Computational Mechanics, vol. 34, pp. 484-502, 2004/11/01 2004.

[13] N. F. Adull Manan, J. Mahmud, and M. H. Ismail, "Quantifying the Biomechanical Properties of Bovine Skin under Uniaxial Tension," Journal of Medical and Bioengineering, vol. 2, pp. 45-48, March 2013 2013. 